\title{
Dispositivos infocomunicacionais em saúde
}

\author{
Infocommunicative Devices in Health or health area
}

Regina Marteleto(a)

Helena Maria Scherlowski Leal David (b)

Mariana Bteshe ${ }^{(c)}$

Nada nos seduz, nada nos atrai; nada desperta nosso ouvido, e nada cativa o nosso olhar; nada por nós é escolhido na profusão das coisas, e nada pode abalar nossa alma, que não esteja, de algum modo, ou preexistindo em nosso ser ou secretamente sendo almejado pela nossa natureza ${ }^{1}$ (p.101).

Pesquisas conduzidas pelo grupo Cultura e Processos Infocomunicacionais (Culticom) $^{1,(d)}$, do Programa de Pós-Graduação em Ciência da Informação do Instituto Brasileiro de Informação em Ciência e Tecnologia (IBICT) e a Escola de Comunicação (ECO) da Universidade Federal do Rio de Janeiro (UFRJ) - PPGCI/ IBICT-UFRJ, com apoio em práticas de construção compartilhada do conhecimento, produzem experimentos que visam representar o universo de questões, vivências e interesses de populações de periferias urbanas em torno da problemática da saúde. No período entre 2004 e 2011 o grupo criou o Almanaque da Dengue, o Zine Violento e o Almanaque do Agente Comunitário de Saúde, em diferentes projetos de pesquisa. Eles são chamados de "dispositivos de informação e comunicação em saúde" no sentido de que um dispositivo é, na sua essência, um agenciamento de elementos com a intenção de articular meios em função de uma finalidade ligada a uma situação, a qual exerce constrangimentos e impõe limites ${ }^{2,3}$.

\footnotetext{
(a) Instituto Brasileiro de Informação em Ciência e Tecnologia, Programa de Pós-Graduação em Ciência da Informação/ PPGCI. Rua Lauro Muller, 455 Botafogo, Rio de Janeiro, RJ 22290160 Brazil.regina.mar@terra. com.br

(b) Universidade do Estado do Rio de Janeiro (UERJ), Faculdade de Enfermagem. helenalealdavid@gmail.

(c) Fundação Oswaldo Cruz - Escola Nacional de Saúde Pública. marianabteshe@gmail.com

(d) Grupo de pesquisa Cultura e Processos Infocomunicacionais: http://plsql1.cnpq. br/buscaoperacional/ detalhegrupo.jsp?grupo= 0026607DLU6GNX
} 


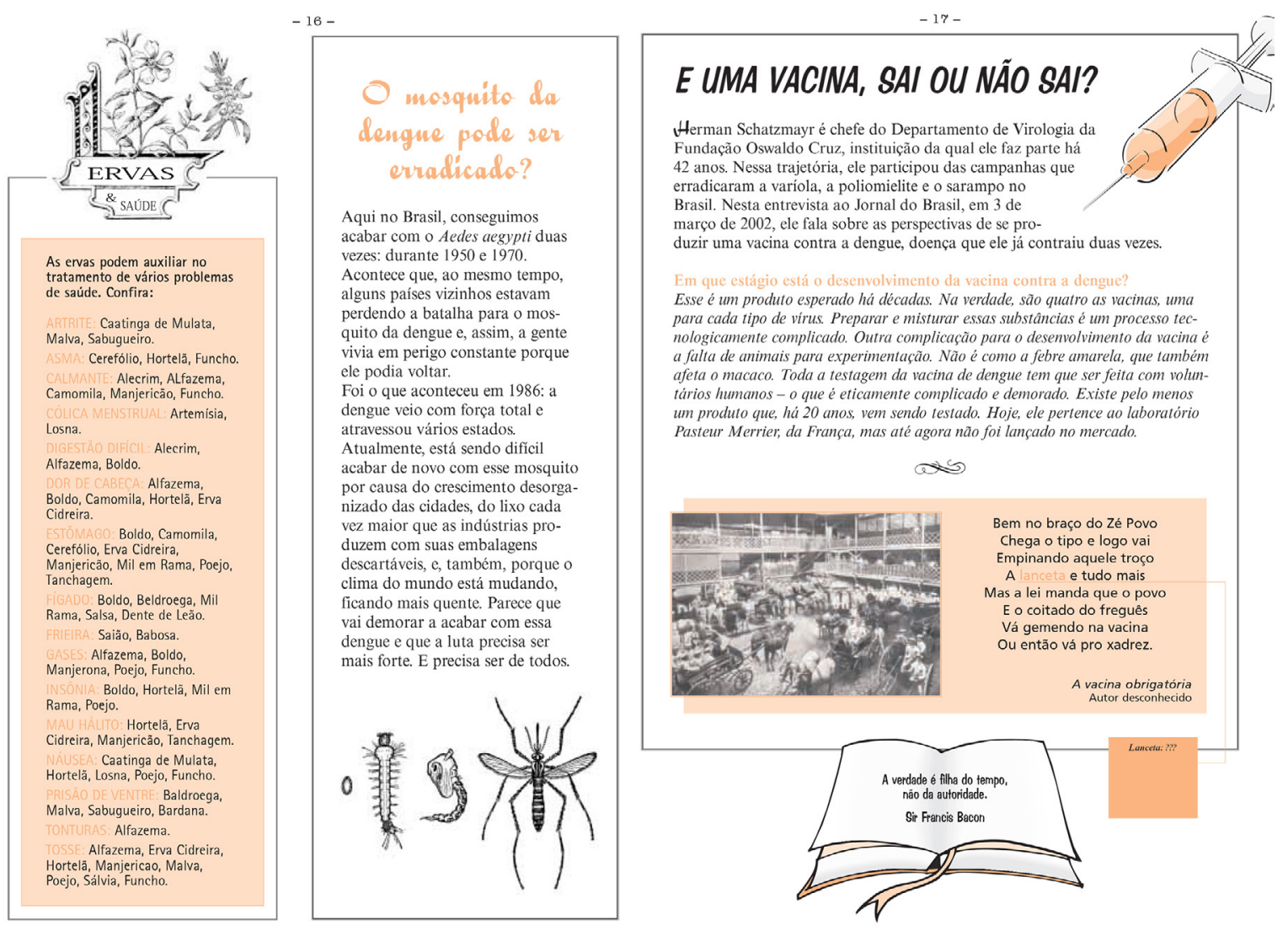

Figura 1. Formas híbridas da informação científica e do saber popular expressas em imagens, ilustrações, provérbio e música.

Um dispositivo é, portanto, algo inscrito em um projeto, tendo uma missão ou finalidade a cumprir, numa situação particular, o que representa a sua força fundante e sua razão de ser, tanto quanto as limitações que pesam sobre os seus objetivos ${ }^{4}$. 


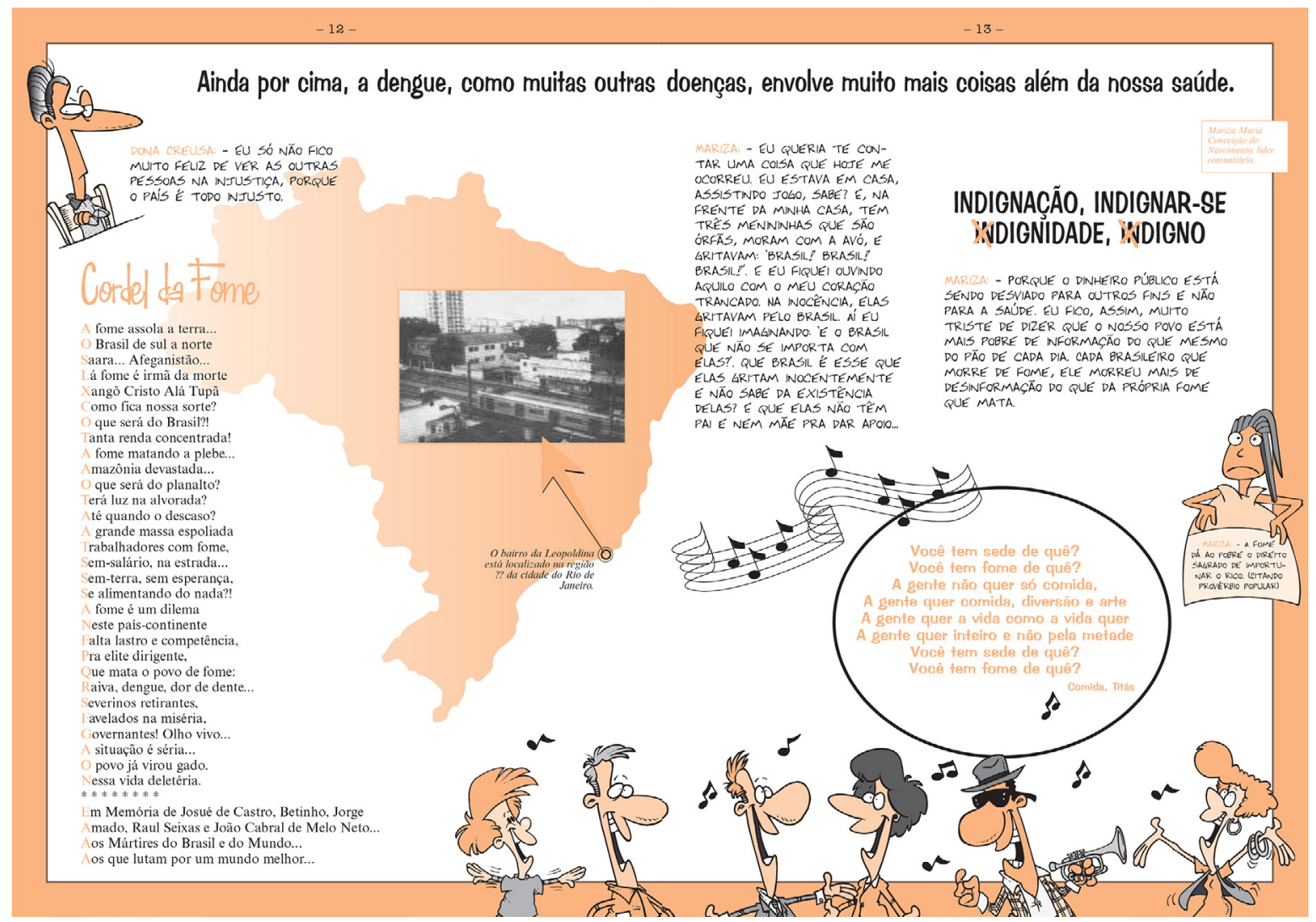

Figura 2. Por meio de um eixo reflexivo o dizer popular aciona uma figuração textual e imagética das questões de saúde.

Os dispositivos teriam potencial de reavivar saberes e práticas em saúde presentes na cultura de um povo, país ou comunidade para gerar um "terceiro conhecimento", quando em diálogo com outras formas de saber - o científico, o jornalístico, o literário, o artístico, por exemplo. A linguagem hipertextual é empregada para representar as redes sociais, cognitivas e semânticas desses diálogos de saberes. Por isso, a importância do emprego de diferentes linguagens (verbal e imagética) e o incentivo do trânsito entre elas, baseados no princípio de que o leitor ou expectador é sempre ativo no processo de interpretação das imagens e dos textos. Mais do que um suporte técnico-metodológico, o dispositivo pode ser um meio de expressão a ser apropriado pelos interlocutores, na articulação intersemiótica entre formas de representação da cultura criada e vivida 5 .

\section{Por que os Almanaques?}

O Almanaque foi o formato escolhido para dois dispositivos - o Almanaque da Dengue e o Almanaque do Agente Comunitário de Saúde - por ser um gênero informacional que se aproxima de uma forma narrativa híbrida, mesclando diferentes tipos de saberes, suportes imagéticos (fotos, ilustrações, etc.) e elementos textuais (populares, científicos, literários, poéticos, jornalísticos, etc.). Desde sempre, o almanaque é uma enciclopédia ou um hipertexto popular. 

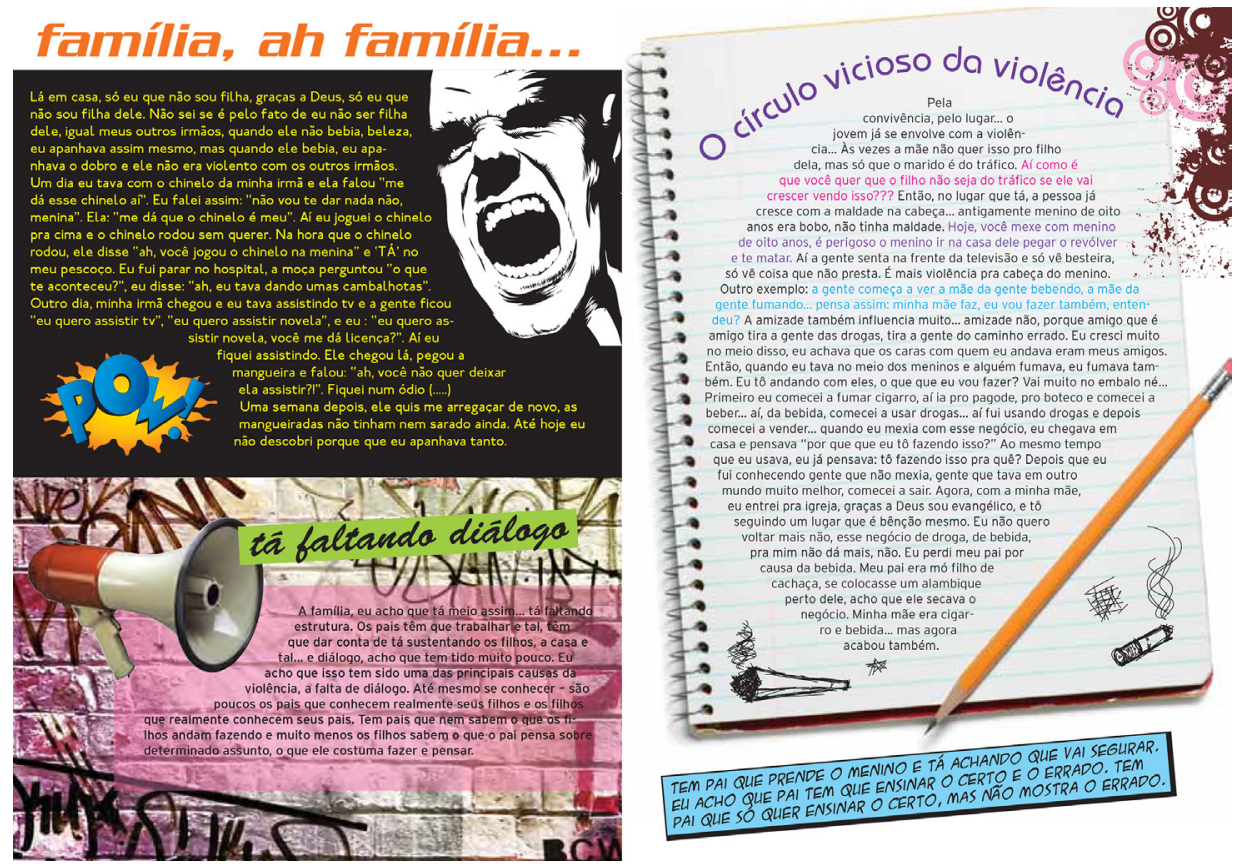

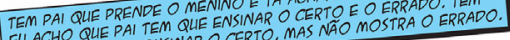
EA ACHO QUL QUES SN

Figura 3. Jovens associam a violência às vivências familiares e sociais. Emprego de imagens e ilustrações contrastando o diálogo e a agressão verbal e/ou física.
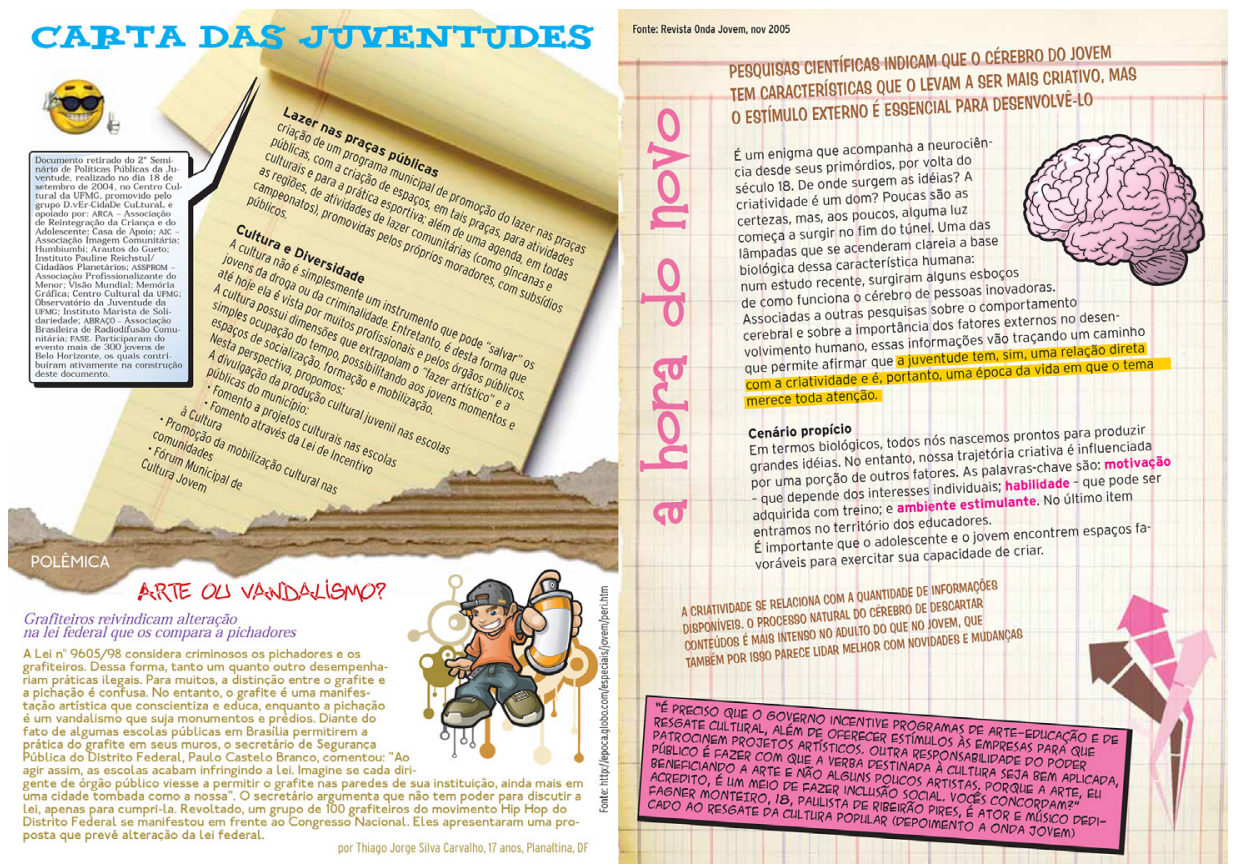

Figura 4. A arte é abordada em suas diferentes facetas - lazer, cultura e criatividade - como mediação para expressar a violência cotidiana. 


\section{Por que o Zine?}

O Fanzine é um formato de comunicação que reflete os modos de interação e expressão dos jovens. Por isso o Zine Violento foi construído como mediador da temática da violência associada à identidade, ao território e às redes de interação de jovens de periferias das grandes cidades. A arte surge como meio para enxergar o contraste entre as máscaras (a realidade que se mostra e que se esconde) e os espelhos (a realidade que se reflete e que se vive). A linguagem hipertextual é dinâmica, com amplo uso de imagens, símbolos e cores.

\section{rede maré jovem}

Rede Maré Jovem é um movimento de jovens da comunidade da Maré que se propõe a pensar e construir politicas públicas para a juventude, de forma abrangente e articulada, e encaminhar ações que possam aproxim par os jovens un torno de alividades culurats, educativas e promo

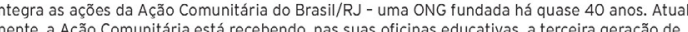
moradores do Complexo de Favelas da Maré e do Conjunto Habitacional de Cidade Alta, sendo. que cerca de $50 \%$ dos seus educadores são moradores locais.

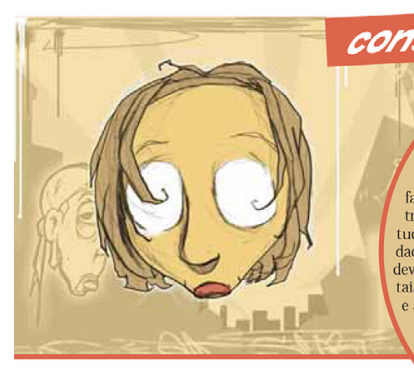

\section{consegtithote}

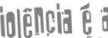

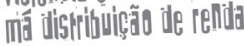

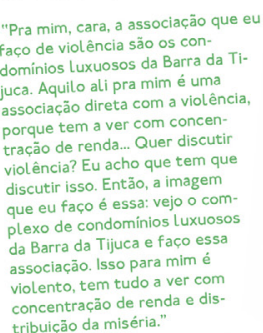
tribuição da misér
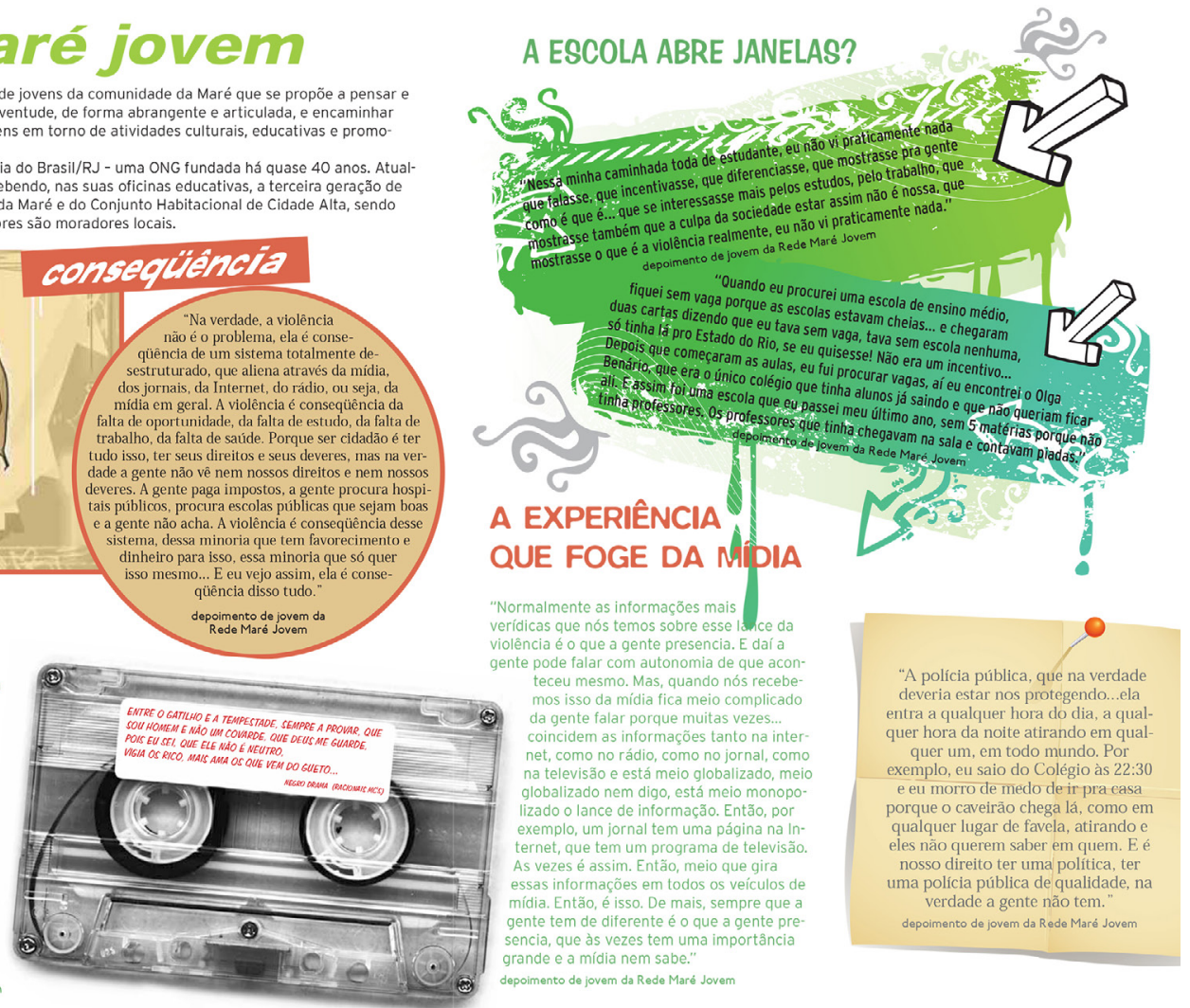

Figura 5. As experiências cotidianas de jovens aparecem como depoimentos alternativos ao discurso midiático. A escola é apresentada como um espaço para troca destas vivências. As linguagens popular e musical reforçam a importância de uma posição crítica dos jovens diante da violência.

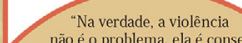
qüência de um sistema totalmente demidia em geral. A violência é consequiência da
Galta de oportunidade, da falta de estudo, da falta rabalho, da falta de saúde. Porque ser cidadão é ter de a gente não vê nem nossos direitos e nem nossos eres. A gente paga impostos, a gente procura hosppiblicos, procura escolas publicas que sejam bor

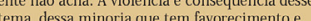
inheiro para isso essa minoria que só quer mesmo. E euvejo assim ela é consesestruturado, que aliena atraves da midia,
dos jornais, da Internet, do rádio, ou seja, da 


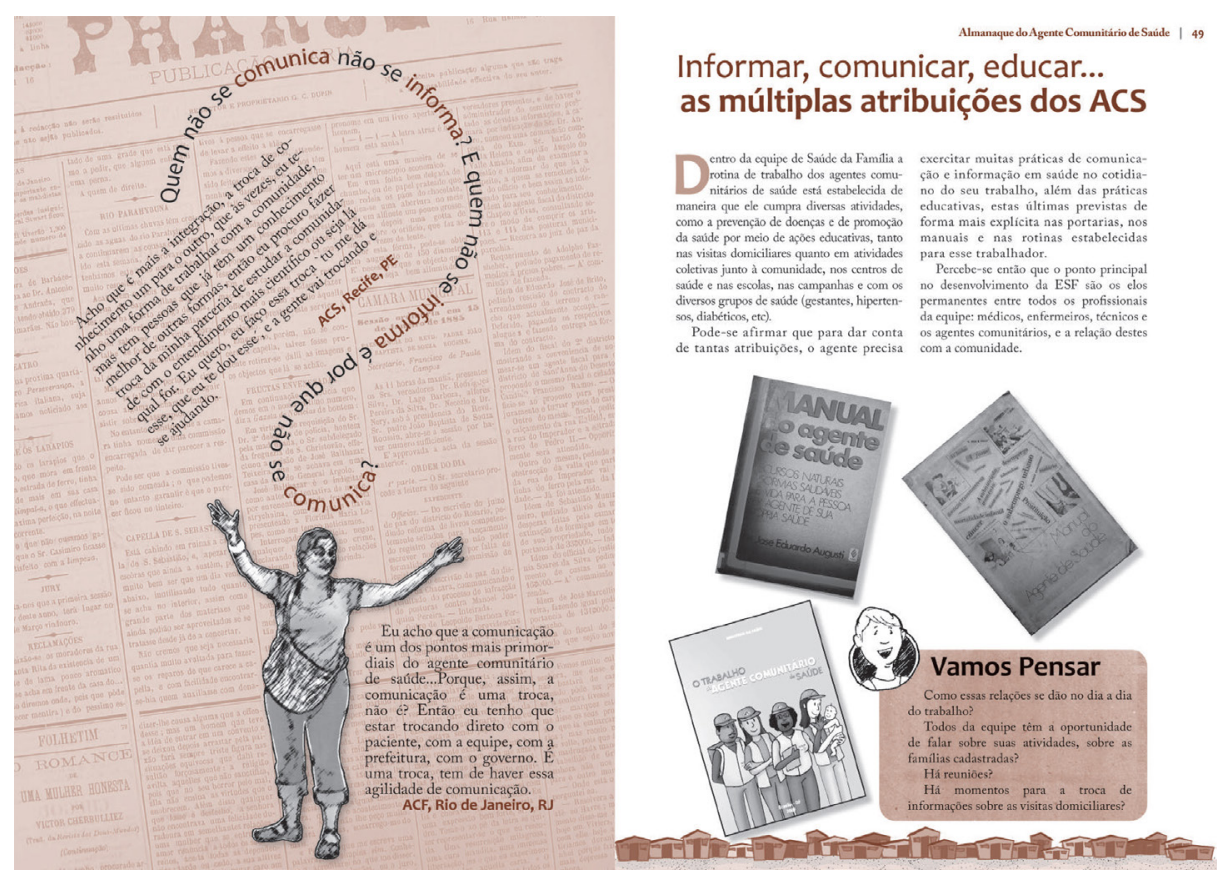

Figura 6. Um jogo de palavras e imagens para provocar conversações entre os ACS sobre a diversidade de suas tarefas.

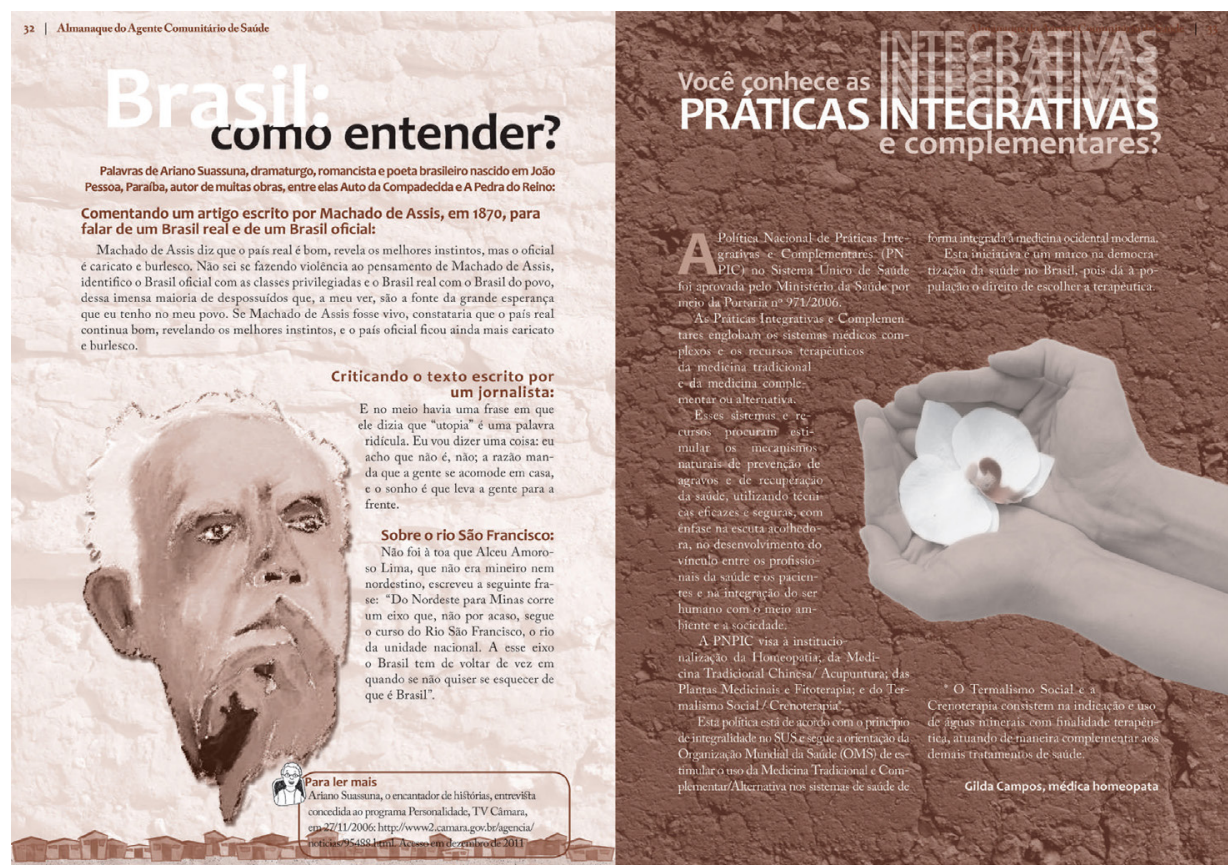

Figura 7. A literatura para refletir sobre o país e a palavra especializada para ampliar o pensamento sobre a saúde. 


\section{Referências}

1. Valéry P. Eupalinos ou o Arquiteto. 34ª ed. Rio de Janeiro, 1996.

2. Foucault M. Le jeu de Michel Foucault [entretien avec D. Colas et al]. Ornicar? Bulletin périodique du champ freudien, n.10, p.62-93, juillet, 1977.

3. Agamben G. Qu'est-ce qu'un dispositif? Paris: Ed. Payot \& Rivages, 2007.

4. Marteleto R, Couzinet V. Mediações e dispositivos de informação e comunicação na apropriação de conhecimentos: elementos conceituais e empíricos a partir de olhares intercruzados. RECIIS - R. Eletr. de Com. Inf. Inov. Saúde. Rio de Janeiro, v.7, n.2, Jun., 2013.

5. Aumont JA. Imagem. Campinas, SP: Papirus, 1993.

Recebido em 04/06/2014. Aprovado em 22/08/2014 
